\title{
As dores e os prazeres da antropologia
}

Paul Stoller. Yaya's story: the quest for well-being in the world. Chicago, The University of Chicago Press, 2014. 157 páginas.

\section{Leonardo Carbonieri Campoy}

Dentre etnografias e teorias, a bibliografia antropológica está pontuada por textos que versam sobre as condições e os significados de ser um praticante desse ofício para, daí, extrair potências heurísticas que esse saber pode oferecer. Distanciando-se das formas consagradas de publicação acadêmica e, ao mesmo tempo, sem cumprirem completamente o projeto ficcional do romance novelesco, os autores desses livros e artigos mesclam memórias, acontecimentos pessoais e ocasióes proporcionadas pelo campo para refletir sobre o que aprenderam fazendo antropologia e sobre o que, para eles, a antropologia pode ensinar aos seus leitores. É o caso de Reflections on fieldwork in Morocco, em que Paul Rabinow relata como compreendeu a si mesmo por meio da compreensão do outro enquanto sua primeira pesquisa se desdobrava no norte da África; de Grief and a headhunter's rage, em que Renato Rosaldo interpreta a força cultural do luto e da raiva por meio de suas experiências etnográficas, entre os Ilongot, nas Filipinas, e dolorosamente pessoais, trazendo ao texto suas reações diante da morte da esposa, Michelle Rosaldo, enquanto ambos estavam em campo; e, talvez o exemplo mais paradigmático, de Tristes tropiques, em que Lévi-Strauss, enquanto traça sua trajetória no planeta e na antropologia, lança seu olhar sobre a condição humana balizada pela diferença, seja cultural, seja entre essa espécie e os gatos.

Yaya's story é mais uma realização deste tipo singular de literatura antropológica. Nesse livro, Paul Stoller - antropólogo norte-americano, professor na West Chester University, que construiu sua carreira a partir de etnografias no oeste africano, sobretudo no Níger, e entre os imigrantes africanos nos Estados Unidos - conta a história de dois homens para, a partir delas, alinhavar lições sobre o que chamou de a busca de bem-estar no mundo. Esses homens são, aquele que dá nome ao livro, Yaya Harouna, nigeriano que o autor conheceu durante suas pesqui- 
sas nos mercados de imigrantes africanos em Nova York, e o próprio antropólogo, Stoller himself. Já as lições são extraídas a partir dos significados que Stoller percebe no encontro com Yaya, principalmente na convergência estabelecida pela doença. Ambos, em momentos distintos, passaram pela experiência do câncer. A maneira como enfrentaram as vicissitudes dessa condição, de acordo com suas respectivas trajetórias de vida, completamente distintas uma da outra, subsidiam a reflexão de Stoller sobre o que significa se sentir bem consigo mesmo ou, como escreve, usando a expressão daquele que chama de professor, o mestre curandeiro e feiticeiro Songhay Adamu Jenitongo, "sentir-se confortável em sua própria pele"1 (p. 1). O encontro com Yaya permite ao autor elaborar um argumento bastante provocativo para a antropologia, um saber propulsionado eminentemente pela diferença: a doença pariu a semelhança entre dois homens individual, social e culturalmente diferentes.

As reflexões e os argumentos de Stoller são construídos ao longo de nove capítulos, divididos em três partes, além de prólogo e epílogo abrindo e fechando a obra. Na primeira parte, "uma história de vida no comércio", o autor relata o percurso que levou Yaya Harouna e seus dois irmãos de Tillaberi, Níger, onde nasceram, até os mercados de arte africana, em Nova York. Contudo, mais do que uma coleção de fatos dispostos em ordem cronológica, o relato de Stoller é deveras sociológica e antropologicamente orientado, localizando as decisões individuais em contextos sociais e ensaiando interpretações históricas e simbólicas para dar conta das condições que determinaram a vida de Yaya. Assim, é especialmente interessante observar como Stoller trata do fato de que, para Yaya, as peças de arte que ele comercializava nos Estados Unidos - máscaras Songhay talhadas em madeira, antigos adereços Tuaregue feitos de ferro e até mesmo estátuas de terracota Bura do século XI, saqueadas de sítios arqueológicos - eram apenas commodities de alto valor comercial, sem qualquer relevância estética, religiosa e patrimonial. Essa contradição é aparente porque, de acordo com Stoller, como Yaya é um muçulmano criado na tradição dos grandes mercados do oeste africano, ele simplesmente encontrou no interesse norte-americano pela arte dita primiti- va um meio de produção de riqueza por intermédio do comércio, uma atividade de forte prestígio social segundo o islamismo. Amparado pelas relações de parentesco misturadas com obrigações contratuais, Yaya seguiu seus irmãos e, deixando suas duas esposas e vários descendentes no Níger, para onde ele mandava dinheiro e viajava frequentemente, foi aos Estados Unidos vender o que os norte-americanos queriam, entregando as peças por todo o país ou comercializando-as em grandes centros comerciais de africanos em Nova York, nas regiōes do Harlem ou de Chelsea, onde Stoller o conheceu.

$\mathrm{Na}$ segunda parte, "uma história de vida na antropologia”, Stoller é o personagem de Stoller. Nela, o leitor descobre que o autor, neto de imigrantes judeus da Bielorrússia que conseguiram estabelecer condições relativamente prósperas nos Estados Unidos por meio do trabalho na construção civil, deparou-se com a antropologia como resultado de um conflito familiar desdobrado no contexto nacional da guerra do Vietnã. Na universidade, enquanto seus pais queriam que ele seguisse a carreira de advogado, Stoller queria mais e mais se aprofundar no existencialismo de Sartre e na fenomenologia de Merleau-Ponty. A graduação estava chegando ao fim e, com o perigo de ser recrutado para lutar em uma guerra com a qual não concordava, o pacifista Stoller encontrou nos intercâmbios promovidos pelos Peace Corps um modo de adiar a resolução do conflito familiar e, ao mesmo tempo, escapar do Vietnã. Depois de passar dois anos no Níger ensinando inglês e, de relance, tendo acesso a realidades jamais imaginadas, o autor viaja ao seu país natal decidido a se organizar para voltar ao continente africano, desta vez como etnógrafo. Assim começa mais uma daquelas simbioses entre um antropólogo e uma etnia, entre Stoller e os Songhay do Níger, mas, nesse caso, profundamente marcada por uma afinidade pessoal entre o autor e Adamu Jenitongo, um curandeiro e feiticeiro com quem ele estabelece uma relação de aluno e professor que perdura até a morte do mestre. Ao longo dos eventos que sucederam o falecimento de Jenitongo, Stoller conta que os sintomas da malária se manifestaram em seu corpo. Curandeiros nigerianos lhe disseram que aquilo era uma "doença que não era doença" (p. 99), ele havia sido amaldiçoado por feitiçaria porque era 
um estrangeiro que conheceu demais as técnicas Songhay pelos ensinamentos de Jenitongo. Com medo das dores e dos feitiços, Stoller deixa o Níger em 1990 para voltar a esse país somente em 2008. É justamente aí, ao longo desses dezoito anos, que começa a visitar os imigrantes africanos nos Estados Unidos, quando conhecerá, então, Yaya Harouna.

Stoller conta a história de sua vida ritmando-a com o refrão da revelação transformacional. Quando se deparou pela primeira vez com um espírito Hauka, quando conheceu o mestre Jenitongo e quando sofreu a "doença que não era doença", ele escreve que, nessas ocasiôes, sentiu "guinadas existenciais em seu ser" (p. 82) que "mudaram incomensuravelmente" (p. 79) sua vida. Esse mesmo acorde dá o tom da derradeira e mais importante parte do livro, sugestivamente intitulada "despertares" - awakenings -, em que o autor narra as experiências dos dois homens com o câncer e elabora uma interpretação acerca do cruzamento das trajetórias de ambos nesse momento delicado de suas vidas. Utilizando-se da metáfora da passagem da "aldeia dos saudáveis para a aldeia dos doentes" (pp. 107-115), Stoller gasta poucas páginas para relatar como, após descobrir que seu corpo abrigava um linfoma, um tratamento quimioterápico conseguiu controlar eficazmente esse tipo de câncer que, segundo a biomedicina, não tem cura definitiva. Contudo, o nódulo dessa parte está nos capítulos 8 e 9 - "três anos nas sombras" e "uma notável convergência”, respectivamente -, dedicados às experiências de Yaya acompanhadas por Stoller. É difícil tratar desse trecho do livro sem antecipar algumas informações e, assim, quebrar o efeito que o autor certamente quis imprimir na leitura do seu texto. Suficiente assinalar, portanto, que Stoller, já recuperado, procura ajudar Yaya a lutar contra um câncer intestinal que teima em crescer, apesar do qualificado atendimento que recebe nos Estados Unidos, seja angariando informações sobre a doença e repassando ao amigo, seja pesquisando maneiras para que o africano consiga retirar um visto de paciente para conduzir legalmente seu tratamento em terras norte-americanas. O desfecho acontece quando Yaya, depois de batalhar sem sucesso contra o câncer por três anos, decide voltar para o Níger e ficar com seus parentes. Ele conta a decisão para Stoller em um encontro como qualquer outro que ambos tinham nos mercados nova-iorquinos de arte africana. Stoller escreve que, olhando profundamente em seus olhos, Yaya tocou em sua mão e disse solenemente: "Paul, [...] eu estou indo para casa” (p. 135). Aí, nesse momento, o autor identifica a notável convergência.

Em nosso último encontro, Yaya e eu vivenciamos um raro ponto de convergência existencial, uma tempestade perfeita de compreensão mútua. Como todas as experiências paroxísmicas na vida, essa durou apenas alguns momentos; para mim, esses momentos são inesquecíveis. Esses momentos me mudaram. Eles reafirmaram em mim a crença de que seres humanos com histórias distintas podem sobrepujar diferenças substanciais e estabelecer laços profundos de compreensão mútua (p. 136).

Sem saber dizer se Yaya sentiu o mesmo que ele, Stoller entende que a doença dissipou as diferenças entre os dois homens e, por alguns segundos, os nivelou. Naquela ocasião, o câncer foi um solvente das distintas trajetórias sociais e identidades culturais que marcavam esses homens, galvanizando suas existências em uma semelhança profundamente sentida por Stoller como um despertar. Pode-se afirmar, portanto, que a busca por bem-estar que está no subtítulo do livro encontra-se, para Stoller, na decisão de Yaya abrir mão do tratamento de uma doença terminal para ficar com os seus e, para o próprio autor, de reconhecer, após uma vida analisando as diferenças, que os seres humanos guardam alguma semelhança.

No prólogo, Stoller escreve que a busca por bem-estar é o produto de certa inquietude - restless -, que constantemente lança o indivíduo que a sente ao novo e ao risco, justamente para se sentir confortável em sua própria pele (pp. 1-9). Yaya's story certamente se mostrará como uma obra encantadora para aqueles antropólogos que se sentem inquietos com uma antropologia que, muitas vezes, tem dificuldade de se comunicar com o público não especializado e que parece não querer pensar, junto com as diferenças, também a semelhança. 


\section{Notas}

1 Todas as traduções são minhas. Quando as expressões utilizadas pelo autor oferecerem múltiplas possibilidades de tradução, elas serão indicadas.

\section{BIBLIOGRAFIA}

LEVI-STRAUSS, C. (1955), Tristes tropiques. Paris, Plon.

RABINOW, P. (1977), Reflections on fieldwork in Morocco. Berkeley, University of California press.

ROSALDO, R. (1989), "Grief and a headhunter's rage", in — Culture and truth: the remaking of social analysis. Boston, Beacon Press.

\section{LEONARDO CARBONIERI CAMPOY}

é doutorando em sociologia e antropologia pela Universidade Federal do Rio de Janeiro (UFRJ) e bolsista Faperj. E-mail: leocampoy@gmail.com.

DOI: http//dx.doi.org/10.17666/3190172-175/2016 